\title{
Hour Times Picogram per Milliliter per Kilogram
}

National Cancer Institute

\section{Source}

National Cancer Institute. Hour Times Picogram per Milliliter per Kilogram. NCI

Thesaurus. Code C85636.

Hours times picograms per milliliter per kilogram. 